\title{
Hand eczema among healthcare workers in Guangzhou City: a cross-sectional study
}

\author{
Danqi Huang ${ }^{1}$, Zengqi Tang ${ }^{1}$, Xiaonan Qiu ${ }^{1}$, Xiuting Liu ${ }^{1}$, Zhixuan Guo ${ }^{1}$, Bin Yang $^{2}$, Qing Guo ${ }^{1}$, \\ Hui Xiong ${ }^{1,3}$
}

${ }^{1}$ Department of Dermatology, Sun Yat-sen Memorial Hospital, Sun Yat-sen University, Guangzhou, China; ${ }^{2}$ Department of Dermatology, Dermatology Hospital of Southern Medical University, Southern Medical University, Guangzhou, China; ${ }^{3}$ Guangdong Provincial Key Laboratory of Malignant Tumor Epigenetics and Gene Regulation, Sun Yat-sen Memorial Hospital, Sun Yat-sen University, Guangzhou, China

Contributions: (I) Conception and design: H Xiong, Q Guo; (II) Administrative support: Q Guo, B Yang; (III) Provision of study materials or patients: D Huang, Z Tang; (IV) Collection and assembly of data: D Huang, X Qiu; (V) Data analysis and interpretation: X Liu, Z Guo; (VI) Manuscript writing: All authors; (VII) Final approval of manuscript: All authors.

Correspondence to: Qing Guo; Hui Xiong. Department of Dermatology, Sun Yat-sen Memorial Hospital, Sun Yat-sen University, Guangzhou, China. Email: guoqingzsy@163.com; xionghui89@163.com.

\begin{abstract}
Background: Healthcare workers are at high risk of developing hand eczema. This study aimed to investigate the association between occupational hygiene and self-reported hand eczema among nurses and doctors in Guangzhou.

Methods: A cross-sectional study using a self-administrated questionnaire sent to 740 health care workers in two tertiary hospitals between $1^{\text {st }}$ April and $1^{\text {st }}$ July 2019 was conducted.

Results: In total, 521 healthcare workers responded (70.4\%). The prevalence of self-reported hand eczema was $9.6 \%$ [95\% confidence interval (CI): 7.1-12.1\%], with $10.8 \%$ in nurses and $6.9 \%$ in doctors. According to multivariable logistic regression analysis, the prevalence was higher in those who were excessively exposed to hair dye (OR: 3.871, 95\% CI: 1.106-13.549) and those having a history of food allergy were at 3.013 (95\% CI: 1.314-6.907) times greater risk of having hand eczema than those who did not. The odds of having hand eczema were 4.863 (95\% CI: 1.037-22.803) times greater in those who hand washed more than 50 times daily in comparison to those who washed hands less than 10 times per day. The symptoms of hand eczema were mild during the investigation period.
\end{abstract}

Conclusions: Hand eczema is common among healthcare workers in Guangzhou. The prevention of hand eczema by educational programs is needed for Chinese healthcare workers.

Keywords: Hand eczema; healthcare workers; prevalence; risk factors

Submitted Nov 03, 2020. Accepted for publication Dec 13, 2020.

doi: $10.21037 /$ atm-20-7652

View this article at: http://dx.doi.org/10.21037/atm-20-7652

\section{Introduction}

Hand eczema is a recurrent inflammatory disease characterized by erythema, papules, vesicles, scaling, fissures, itch, and pain (1), resulting in cosmetic defects, psychological distress $(2,3)$, and a significant economic burden (4,5). Genetic and environmental factors play a role in the etiology and prognosis of hand eczema and domestic conditions including the use of cleansers and caring for children under 4 years old (6) may exacerbate its prevalence and severity. Heede $e t$ $a l$. found that a history of atopic dermatitis, filaggrin gene null mutations and contact sensitization were associated with the persistence of hand eczema (7). The incidence of hand eczema is $5-8 \%$ (8) among the general population worldwide. It is more common in healthcare workers, chefs, and hairdressers whose occupations involve heavy wet work (9) and frequent hand washing with a prevalence rate of $6-80 \%$ (10) although the risk factors influencing occupational hand eczema have changed over time (11). 
Hand eczema in healthcare workers may promote the carriage of microorganisms on eczematous skin before transmission to patients $(12,13)$. Healthcare workers have been shown to benefit from skin-care education and individual counseling (14) and in Denmark and Germany an evidencebased skin protection program has been carried out in hospitals (15-18). While the prevalence rate of hand eczema in Harbin, Zhenjiang and Shijiazhuang cities has been reported to be $20 \%$ (19), $17.7 \%$ (20), and $22.3 \%$ (21) respectively, there is little data on its prevalence in health care workers, possibly because little attention is paid to the disease. In this study, we aimed to investigate the incidence, clinical features, and risk factors of hand eczema among health care workers in Guangzhou, Southern China. We present the following article in accordance with the SURGE reporting checklist (available at http://dx.doi.org/10.21037/atm-20-7652).

\section{Methods}

\section{Study design and participants}

A cross-sectional survey was conducted among nurses and doctors randomly selected from the lists of medical staff in two tertiary hospitals, one general and one dermatology specialized hospital, between $1^{\text {st }}$ April and $1^{\text {st }}$ July 2019. There were no exclusion criteria and ethical approval was obtained through the Sun Yat-sen Memorial Hospital Ethics Committee. The researchers approached randomly selected health care workers to explain the study and signed an informed consent form with them. The study was in accordance with the Declaration of Helsinki (as revised in 2013).

\section{Sample size calculation}

Calculation of the sample size was based on a Swedish study among physicians and nurses of which the hand eczema prevalence rate was $21.1 \%$ (22). The confidence level was 0.95 and the allowed error was 0.03 . The two-sided test was performed on PASS version 15 (NCSS, LLC. Kaysville, Utah, USA) and it was determined that 740 participants were required. As the total number of nurses and doctors in the general hospital was 19 times that of the dermatology specialized hospital, 703 and 37 participants respectively from each hospital were randomly selected.

\section{Randomization}

Random numbers for each healthcare worker were generated by SPSS version 25 (IBM, Armonk, NY, USA) software after the random seed was set as 12345 and the uniform distribution on the interval $(0,100)$. Random numbers were sorted in ascending order and the first 740 healthcare workers then selected.

\section{Questionnaires and hand eczema estimation}

The investigators distributed the paper vision of the questionnaire to the randomly selected medical staff and collected the questionnaire on the same day or the next day if partitioners were too busy to fill the questionnaire. No incentives were provided. The questionnaire was modified from the Nordic Occupational Skin Questionnaire (NOSQ2002) designed for surveying work-related skin disease (23). It was used to obtain demographic data and information on occupational wet work exposure (hand washing, use of soap and alcohol-based hand hygiene solutions, hours wearing disposable gloves), and possible confounding factors (history of allergic disease, lifestyle factors, domestic wet work exposures). Daily hand washing times were categorized as $0-10,10-20,20-50$ and more than 50 and the number of alcoholic hand disinfectant uses as no more than 5, 6 to 10 , and more than 10. The hours of wearing disposable gloves was stratified into three groups: no more than 1 hour, $1-4$, 2-6 and more than 6 hours. The number of hours spent looking after children under 4 years old was grouped as no more than 0.5 hours and above.

Self-reported hand eczema was defined as an affirmative answer to the question "Have you had hand eczema during the past 12 months?" Questionnaires without an answer to this question were seen as partial interviews and questionnaires with answers to all questions were regarded as complete interviews. If the response to this question was yes, the following additional questions were asked: 'Which symptoms do you have, erythema, papule, vesicles, scaling, fissures, itch or pain?'; 'Do you have eczema in other parts of your body?'; 'Which season does your hand eczema occur most frequently?'; 'Did you ever turn to a dermatologist for help?'; 'Have you changed your behavior to avoid hand eczema?'; 'How much did it cost to cure your hand eczema?'; 'To what extent did hand eczema affect your life and work?'; 'Have you ever changed your profession because of hand eczema?'; 'Did you ever take sick leave because of hand eczema?'

Participants who reported they currently had hand eczema were invited to take a patch test (Sanming Hezhong Biotechnology Company, Fujian), fluorescence 
Table 1 Demographic and work characteristics [n (\% of total)]

\begin{tabular}{|c|c|c|c|}
\hline \multirow{2}{*}{ Variable } & \multicolumn{2}{|c|}{ Hand eczema } & \multirow{2}{*}{$P$} \\
\hline & No $(\mathrm{N}=471)$ & Yes $(\mathrm{N}=50)$ & \\
\hline Age (years) & $32.6 \pm 7.9$ & $32.3 \pm 7.9$ & 0.803 \\
\hline Sex & & & 0.151 \\
\hline Male & $77(14.8)$ & $4(0.8)$ & \\
\hline Female & 394 (75.6) & $46(10.5)$ & \\
\hline Hospital & & & 1.000 \\
\hline General & 446 (85.6) & $48(9.2)$ & \\
\hline Specialized & $25(4.8)$ & $2(8.0)$ & \\
\hline Profession & & & 0.363 \\
\hline Nurse & $323(62.0)$ & $39(7.5)$ & \\
\hline Doctor & $148(28.4)$ & $11(2.1)$ & \\
\hline Education & & & 0.922 \\
\hline Specialty & $81(15.5)$ & $7(1.3)$ & \\
\hline Undergraduate & 273 (52.4) & $31(6.0)$ & \\
\hline Postgraduate & $73(14.0)$ & $7(1.3)$ & \\
\hline Doctor degree & $44(8.4)$ & $5(1.0)$ & \\
\hline Working years & $9.7 \pm 8.1$ & $10.7 \pm 9.1$ & 0.374 \\
\hline Working shift & & & 0.898 \\
\hline Day shift & $222(42.6)$ & $24(4.6)$ & \\
\hline Night shifts & $15(2.9)$ & $1(0.1)$ & \\
\hline Three shifts & 234 (44.9) & $25(4.7)$ & \\
\hline
\end{tabular}

microscopic examination of fungi, trans-epidermal water loss measurement (Gpskin, Neopharm, USA), Dermatology Life Quality Index (DLQI) scoring, and Hand Eczema Severity Index (HECSI) scoring. The DLQI questionnaire (24), consisting of ten questions, gathered information on the impact of hand eczema on life quality with higher scores indicating a greater impact. The HECSI (25) scoring system assessed the severity (scale $0-3$ ) of six symptoms (erythema, papule, vesical, fissure, scaling, fissure and edema) and lesioned areas (scale 1-4) in five parts of the hand (fingertip, finger, palm, the back and wrist).

\section{Statistics analysis}

All data were analyzed by IBM SPSS Statistics version 25.0. The response rate was equal to the number of complete interviews divided by the number of interviews (complete plus partial) plus the number of non-interviews. Quantitative variables were described as the median together with standard deviation, and categorical variables were described as relative frequency and absolute numbers. Quantitative variables were compared by two independent $t$ test and categorical variables by $\chi^{2}$ test. We used binary logistic regression to exam the risk factors for hand eczema. Only variables with $\mathrm{P}$ values under 0.2 and hours of wearing disposable gloves were included in multiple regression analyses. Multivariate-adjusted ORs and $95 \%$ CIs were given, and a statistical significance set at $\mathrm{P}<0.05$ was considered statistically significant. Imputation for missing data was not performed.

\section{Results}

\section{Characteristics of participants}

Of the 740 invited healthcare workers, 70.4\% [524] responded to the questionnaires. After three incomplete surveys without answers to the question "Have you had hand eczema on any occasion during the past 12 months?" were removed, 521 complete surveys remained for further analysis. Females composed $84.5 \%$ of respondents, $69.5 \%$ were nurses, and $94.8 \%$ were from the general hospital. The average age and working years of participants was $32.5 \pm 7.9$ and $9.8 \pm 8.2$ years respectively and $60 \%$ of respondents reported having a bachelor's degree (Table 1). Our participants came from 68 departments (data not shown) and no differences were observed in the prevalence of hand eczema among medical staff in different departments.

\section{Risk factors for hand eczema}

All variables were analyzed with univariate logistic regression (Table 2 and Table S1) and variables with a $\mathrm{P}$ value $<0.4$ and time spent wearing disposable gloves (hours daily) were simultaneously included in the multivariable model since wearing disposable gloves was reported to be closely related with hand eczema (22). Table 2 shows that the frequent use of hair dye $(\mathrm{P}=0.011)$ and presence of food allergy $(\mathrm{P}=0.002)$ are the most common and significant risk factors for hand eczema in participants even after the adjustment of multiple variants including sex, hours of wearing disposable gloves, use of soap and alcohol-based hand hygiene solutions, and hours of caring for children. Additionally, with hand washing less than 10 times daily as a reference, the OR and $95 \%$ CI of washing hands more than 
Table 2 Association between risk factors and hand eczema- logistic regression analysis

\begin{tabular}{|c|c|c|c|c|c|c|}
\hline Variables & \multicolumn{2}{|c|}{ Hand eczema } & \multicolumn{2}{|c|}{ Univariate } & \multicolumn{2}{|c|}{ Multivariate $^{a}$} \\
\hline \multicolumn{7}{|l|}{ Sex } \\
\hline Male & $77(14.8)$ & $4(0.8)$ & 1 & 0.135 & 1 & 0.155 \\
\hline Female & $394(75.6)$ & $46(10.5)$ & $2.419(0.760-7.701)$ & & $2.197(0.742-6.504)$ & \\
\hline$\leq 1$ & $233(44.7)$ & $22(4.2)$ & 1 & 0.537 & 1 & 0.602 \\
\hline $1-4$ & $150(28.8)$ & $17(3.2)$ & $1.264(0.607-2.631)$ & 0.531 & $1.273(0.635-2.551)$ & 0.496 \\
\hline$>4$ & 88 (16.9) & $11(2.1)$ & $1.589(0.694-3.640)$ & 0.274 & $1.470(0.659-3.280)$ & 0.346 \\
\hline \multicolumn{7}{|c|}{ Hand washing (times daily) } \\
\hline $20-50$ & $65(12.5)$ & $8(1.5)$ & $1.148(0.456-2.892)$ & 0.770 & $1.130(0.468-2.729)$ & 0.786 \\
\hline$>50$ & $8(1.5)$ & $3(0.6)$ & $4.760(0.933-24.296)$ & 0.061 & $4.863(1.037-22.803)$ & 0.045 \\
\hline \multicolumn{7}{|c|}{ Alcoholic hand disinfectant use (times daily) } \\
\hline$\leq 5$ & $262(50.4)$ & $33(6.3)$ & 1 & 0.190 & 1 & 0.274 \\
\hline $5-10$ & $96(18.5)$ & $9(1.7)$ & 0.687 (0.291-1.622) & 0.391 & $0.751(0.334-1.685)$ & 0.487 \\
\hline$>10$ & $112(21.5)$ & $8(1.5)$ & $0.431(0.170-1.091)$ & 0.076 & $0.481(0.193-1.194)$ & 0.114 \\
\hline \multicolumn{7}{|c|}{ Caring children under 4 years old (hours daily) } \\
\hline$\leq 0.5$ & $312(59.9)$ & $29(5.6)$ & 1 & 0.131 & 1 & 0.151 \\
\hline \multicolumn{7}{|c|}{ Food allergy } \\
\hline No & $434(83.3)$ & $40(7.7)$ & 1 & 0.002 & 1 & 0.009 \\
\hline Yes & $37(7.1)$ & $10(1.9)$ & 3.953 (1.628-9.600) & & $3.013(1.314-6.907)$ & \\
\hline \multicolumn{7}{|c|}{ Allergic conjunctivitis } \\
\hline No & $460(88.3)$ & $47(9.0)$ & 1 & 0.102 & 1 & 0.181 \\
\hline Yes & $11(2.1)$ & $3(0.6)$ & $3.744(0.770-18.195)$ & & $2.584(0.643-10.382)$ & \\
\hline
\end{tabular}

a , variables that had a $\mathrm{P}$ value $<0.2$ in the univariate model were simultaneously included in the multivariable model. OR, odds ratio; $\mathrm{Cl}$, confidence interval.

50 times daily was $4.863(1.037-22.803)$.

\section{Characteristics of hand eczema}

The self-reported incidence of hand eczema was $9.6 \%$
(34/521) (95\% CI: 7.1-12.1\%). Of 34 respondents who completed a second questionnaire about their symptoms and clinical history (Table 3), 23 reported seeking help from a dermatologist and all of these were diagnosed as having hand eczema. Skin lesions were reported as mostly located 
Table 3 Characteristics of hand eczema in healthcare workers

\begin{tabular}{|c|c|}
\hline Characteristics & $\mathrm{n}$ \\
\hline \multicolumn{2}{|l|}{ Symptoms } \\
\hline Redness & 10 \\
\hline Vesicles & 0 \\
\hline Swelling & 3 \\
\hline Scale & 9 \\
\hline Fissures & 9 \\
\hline Hyper & 9 \\
\hline Itch & 0 \\
\hline Pain & 4 \\
\hline \multicolumn{2}{|l|}{ Locations of lesions } \\
\hline Palms & 2 \\
\hline Dorsum of hands & 14 \\
\hline Fingers (except fingers tips) & 23 \\
\hline Fingers tips & 6 \\
\hline Wrists & 0 \\
\hline \multicolumn{2}{|l|}{ Other locations involved } \\
\hline None & 23 \\
\hline Foot & 4 \\
\hline Face & 1 \\
\hline Neck & 3 \\
\hline Trunk & 6 \\
\hline Arm & 7 \\
\hline \multicolumn{2}{|c|}{ Which season is hand eczema experienced? } \\
\hline Spring & 4 \\
\hline Summer & 3 \\
\hline Autumn & 1 \\
\hline Winter & 9 \\
\hline The whole year & 21 \\
\hline \multicolumn{2}{|l|}{ Ever consulted a dermatologist? } \\
\hline Yes & 23 \\
\hline No & 9 \\
\hline \multicolumn{2}{|l|}{ Previous treatment } \\
\hline Topical drugs & 20 \\
\hline Systemic drugs & 5 \\
\hline None & 3 \\
\hline
\end{tabular}

Table 3 (continued)
Table 3 (continued)

\begin{tabular}{|c|c|}
\hline Characteristics & $\mathrm{n}$ \\
\hline \multicolumn{2}{|l|}{ Change of lifestyle } \\
\hline Reducing hand washing & 5 \\
\hline Apply moisturizers after hand washing & 12 \\
\hline Avoid touching irritant materials & 13 \\
\hline None & 11 \\
\hline \multicolumn{2}{|l|}{ Cost of hand eczema (yuan/year) } \\
\hline$<500$ & 28 \\
\hline $500-1,000$ & 4 \\
\hline $1,000-3,000$ & 1 \\
\hline \multicolumn{2}{|l|}{ Impact of hand eczema on life and work } \\
\hline None & 5 \\
\hline Mild & 22 \\
\hline Moderate & 3 \\
\hline Severe & 3 \\
\hline \multicolumn{2}{|l|}{ Job change due to hand eczema } \\
\hline No & 33 \\
\hline Yes & 1 \\
\hline \multicolumn{2}{|l|}{ Sick leave due to hand eczema } \\
\hline No & 34 \\
\hline Yes & 0 \\
\hline
\end{tabular}

on the fingers apart from the fingertips, a higher incidence was found during winter, and an overall duration of 5 (1-9.5) years and past 12 months duration of $2.5(0.25-$ $2.5)$ months was reported. Ten respondents did not take action to protect their hands after being diagnosed and 20 were treated with topical drugs, while three stated their therapy was ineffective. The total annual cost of treatment was reported to be less than 500 yuan $(84.8 \%, 28 / 33)$. Hand eczema had slightly limited the lifestyle and affected the daily activities of 22/33 respondents and seriously affected the work and life quality of three. One nurse had changed the department in which she worked, and 19 respondents reported mild depression, anxiety, and sleep disorders because of hand eczema. Patch tests, fluorescence microscopic examination of fungi, DLQI and HECSI scoring were conducted in ten nurses of which seven showed positive patch tests and one displayed a suspicious positive result. While fluorescence microscopic examination 
of fungi was negative for all ten, the median DLQI, and HECSI scores were $1(0-2)$ and $2(1.5-2.5)$ respectively. Three pregnant nurses did not take the examinations and other healthcare workers were too busy or reluctant to take the patch test because of the hot weather.

\section{Discussion}

In China, the prevalence of hand eczema in the general population is $6.99 \%$ (26), which is lower than that of Sweden (9.4\%) (27), Norway (11.3\%) (28) and Denmark $(12 \%)$. Several studies have reported the prevalence of hand eczema among health workers in different regions. A Swedish study involving 12,288 physicians, nurses and auxiliary nurses reported a prevalence of $21 \%$ (response rate $43 \%$ ) (16), which was higher than the $10.8 \%$ seen in our study (response rate $80.2 \%$ ) and that seen in Indian nurses (6.8\%) (29). The incidence of hand eczema among nurses of our study was also lower than that of other Chinese City, including Harbin (19), Zhenjiang (20) and Shijiazhuang (21) cities. The prevalence rate in doctors in our study was $6.9 \%$ and the low response rate of $55 \%$ was likely due to a lack of participation because of their high workload. A survey among dentists from 309 clinics in Kumamoto City, Japan (response rate 36.2\%) showed the prevalence of hand eczema was as high as $36.2 \%$ (30). The variability in these results may be due to different sample sizes, representativeness of the samples, and different prevalence rates in different regions due to many factors such as cold and dry climate.

In the current study, an increased prevalence of hand eczema was observed in those with excessive exposure to hair dye, those with food allergy history, and those frequently washing their hands. Hair dye irritates and damages the skin barrier and may lead to the induction and aggravation of hand eczema. In an American online study among 90,488 nurses, eczema was found to be strongly associated with food allergy, asthma, and hay fever (31). However, possibly due to the limited sample size, no correlation between hand eczema and asthma or hay fever was found in our study.

In agreement with the findings of Smith's study of nurses in Shijiazhuang, China (21) we found no asociation between age, working years, and hours wearing disposable gloves with hand eczema. A previous study suggested a dose-dependent relationship between hand eczema and handwashing with soap and water as well as the use of disposable gloves among healthcare workers (22).
Interestingly, no correlation was noted between the use of disinfectants and the prevalence of hand eczema, indicating the use of disinfectants might be a viable substitute for soap and water handwashing in hand eczema patients (32). Indeed, as shown in a Danish clinical trial, washing hands with disinfectants when there is no visible contamination and moisturizer application improved hand eczema (33). A recent American study also identified that sensitization to chlorhexidine-based hand hygiene products in healthcare workers varied from $0-3 \%$ (34). This suggests that along with hypersensitivity screening, alternative methods for hand hygiene are required to reduce occupational exposure. More well-designed clinical trials like quasi-experimental and randomized trial, either an individual randomized trial or a cluster randomized trial, reporting an agreed standardized set of outcomes (35), are in need to look at the long-term effect of multifaceted interventions for avoiding exposure and risks factors and providing with career guidance.

The early diagnosis and classification of hand eczema helps to identify its cause (36) and appropriate treatment. Whereas, ten participants did not seek specialist dermatological care, most (28/33) spent less than 500 yuan on their treatment compared with the 1,712-9,792 euros reported in other studies (37). Although only one nurse in our study changed her work department, previous studies have reported the job changing rate of healthcare workers was as high as $34 \%$ due to hand eczema, although this was less than some other occupations (38). Patch test results among 120 healthcare workers with hand eczema in Denmark revealed the most frequent allergic substances to be nickel sulfate and thimerosal (39). Seven nurses in the current study showed moderate positive patch test results and one showed a suspicious positive result in our study. In our study, none of the 34 healthcare workers had taken sick leave due to hand eczema while the percentage was $1.7 \%$ in Netherlands (40).

This study has several strengths, including a high response rate which reduced the selection bias and use of a well-representative sample of healthcare workers in tertiary hospitals. In addition, the high educational level of the participants in our study may leads to a convincible estimation of hand eczema popularity. Limitations of the study include its small sample size and enrolment of only two tertiary hospitals, which may not be generalizable to hospitals of other grades or regions. The symptoms reported were also mild because of spontaneous improvement from the increased humidity and exposure 
to ultraviolet radiation during late spring (41) thus the prevalence of eczema might also be underestimated due to recall bias because the survey was not conducted in winter when the disease is at its worse. Finally, the questionnaires used were adapted from published questionnaires and not specifically validated before use in this study.

In conclusion, this study indicates that hand eczema is common among healthcare workers in Guangzhou, especially those excessively exposed to hair dye, those with food allergy history, and those frequently washing their hands. Recommendations for skincare should be incorporated into hand hygiene education for Chinese healthcare workers in the future. In-depth studies to explore the prevalence of hand eczema in a larger group and the interventions to protect health workers from hand hygiene programs are needed.

\section{Acknowledgments}

Funding: This work was supported by the Fundamental Research Funds for the Central Universities (20ykpy109) to HX and Clinical Research initiation Program of Southern Medical University to BY (LC2017PY002). The funder had no role in the design of the study, collection, analysis, and interpretation of data or in writing the manuscript.

\section{Footnote}

Reporting Checklist: The authors have completed the SURGE reporting checklist. Available at http://dx.doi. org/10.21037/atm-20-7652

Data Sharing Statement: Available at http://dx.doi. org/10.21037/atm-20-7652

Conflicts of Interest: All authors have completed the ICMJE uniform disclosure form (available at http://dx.doi. org/10.21037/atm-20-7652). The authors have no conflicts of interest to declare.

Ethical Statement: The authors are accountable for all aspects of the work in ensuring that questions related to the accuracy or integrity of any part of the work are appropriately investigated and resolved. There were no exclusion criteria and ethical approval was obtained through the Sun Yat-sen Memorial Hospital Ethics Committee. The researchers approached randomly selected health care workers to explain the study and signed an informed consent form with them. The study was in accordance with the Declaration of Helsinki (as revised in 2013).

Open Access Statement: This is an Open Access article distributed in accordance with the Creative Commons Attribution-NonCommercial-NoDerivs 4.0 International License (CC BY-NC-ND 4.0), which permits the noncommercial replication and distribution of the article with the strict proviso that no changes or edits are made and the original work is properly cited (including links to both the formal publication through the relevant DOI and the license). See: https://creativecommons.org/licenses/by-nc-nd/4.0/.

\section{References}

1. Agner T, Aalto-Korte K, Andersen KE, et al. Classification of hand eczema. J Eur Acad Dermatol Venereol 2015;29:2417-22.

2. Kouris A, Armyra K, Christodoulou C, et al. Quality of life, anxiety, depression and obsessive-compulsive tendencies in patients with chronic hand eczema. Contact Dermatitis 2015;72:367-70.

3. Marron SE, Tomas-Aragones, L, Navarro-Lopez, J, et al. The psychosocial burden of hand eczema: Data from a European Dermatological Multicenter Study. Contact Dermatitis 2018;78:406-12.

4. Politiek K, Oosterhaven JAF, Vermeulen KM, et al. Systematic review of cost-of-illness studies in hand eczema. Contact Dermatitis 2016;75:67-76.

5. Cazzaniga S, Ballmer-Weber BK, Grani N, et al. Medical, psychological and socio-economic implications of chronic hand eczema: a cross-sectional study. J Eur Acad Dermatol Venereol 2016;30:628-37.

6. Ibler KS, Jemec GB, Agner T, et al. Exposures related to hand eczema: a study of healthcare workers. Contact Dermatitis 2012;66:247-53.

7. Heede NG, Thyssen JP, Thuesen BH, et al. Predictive factors of self-reported hand eczema in adult Danes: a population-based cohort study with 5-year follow-up. Br J Dermatol 2016;175:287-95.

8. Agner T, Elsner P. Hand eczema: epidemiology, prognosis and prevention. J Eur Acad Dermatol Venereol 2020;34 Suppl 1:4-12.

9. Behroozy A, Keegel TG. Wet-work exposure: a main risk factor for occupational hand dermatitis. Saf Health Work 2014;5:175-80

10. Lund T, Flachs EM, Sørensen JA, et al. A job-exposure matrix addressing hand exposure to wet work. Int Arch 
Occup Environ Health 2019;92:959-66.

11. Olesen CM, Anger T, Ebbehøj NE, et al. Factors influencing prognosis for occupational hand eczema: new trends. Br J Dermatol 2019;181:1280-6.

12. Mernelius S, Carlsson E, Henricson J, et al. Staphylococcus aureus colonization related to severity of hand eczema. Eur J Clin Microbiol Infect Dis 2016;35:1355-61.

13. Brans R, Kolomanski K, Mentzel F, et al. Colonisation with methicillin-resistant Staphylococcus aureus and associated factors among nurses with occupational skin diseases. Occup Environ Med 2016;73:670-5.

14. Fisker MH, Agner T, Sørensen JA, et al. Simple, low-cost group-counselling programme vs treatment as usual for patients with newly notified occupational hand eczemaExploratory analyses of effects on knowledge, behaviour and personal resources of the randomized PREVEX clinical trial. Contact Dermatitis 2018;79:127-35.

15. Graversgaard C, Agner T, Jemec GBE, et al. A longterm follow-up study of the Hand Eczema Trial (HET): a randomized clinical trial of a secondary preventive programme introduced to Danish healthcare workers. Contact Dermatitis 2018;78:329-34.

16. Madan I, Parsons V, Ntani G, et al. A behaviour change package to prevent hand dermatitis in nurses working in health care: the SCIN cluster RCT. Health Technol Assess 2019;23:1-92.

17. Soltanipoor M, Kezic S, Sluiter JK, et al. Effectiveness of a skin care programme for the prevention of contact dermatitis in healthcare workers (the Healthy Hands Project): A single-centre, cluster randomized controlled trial. Contact Dermatitis 2019;80:365-73.

18. Breuer K, John SM, Finkeldey F, et al. Tertiary individual prevention improves mental health in patients with severe occupational hand eczema. J Eur Acad Dermatol Venereol 2015;29:1724-31.

19. Zhang D, Zhang J, Sun S, et al. Prevalence and risk factors of hand eczema in hospital-based nurses in northern China. Australas J Dermatol 2018;59:e194-e197.

20. Liu LP, Li Ym, Xu H, et al. Self-administered questionnaire on hand eczema in nurses. Journal of Clinical Dermatology 2014;5:282-5.

21. Smith DR, Wei N, Zhao L, et al. Hand dermatitis among nurses in a newly developing region of Mainland China. Int J Nurs Stud 2005;42:13-9.

22. Hamnerius N, Svedman C, Bergendorff O, et al. Wet work exposure and hand eczema among healthcare workers: a cross-sectional study. Br J Dermatol 2018;178:452-61.

23. Susitaival P, Flyvholm MA, Meding B, et al. Nordic
Occupational Skin Questionnaire (NOSQ-2002): a new tool for surveying occupational skin diseases and exposure. Contact Dermatitis 2003;49:70-6.

24. Finlay AY, Khan GK. Dermatology Life Quality Index (DLQI)--a simple practical measure for routine clinical use. Clin Exp Dermatol 1994;19:210-6.

25. Held E, Skoet R, Johansen JD, et al. The hand eczema severity index (HECSI): a scoring system for clinical assessment of hand eczema. A study of inter- and intraobserver reliability. Br J Dermatol 2005;152:302-7.

26. Wang X, Yang MC, Shi XD, et al. Cross-sectional multicenter study of hand eczema in the outpatient department of dermatology of tertiary-A hospitals. Journal of Practical Dermatology 2019;4:12.

27. Stenberg B, Meding B, Svensson A. Dermatology in public health--a model for surveillance of common skin diseases. Scand J Public Health 2010;38:368-74.

28. Vindenes HK, Svanes C, Lygre SHL, et al. Prevalence of, and work-related risk factors for, hand eczema in a Norwegian general population (The HUNT Study). Contact Dermatitis 2017;77:214-23.

29. Gupta SB, Gupta A, Shah B, et al. Hand eczema in nurses, nursing auxiliaries and cleaners-A cross-sectional study from a tertiary hospital in western India. Contact Dermatitis 2018;79:20-5.

30. Minamoto K, Watanabe T, Diepgen TL. Self-reported hand eczema among dental workers in Japan - a crosssectional study. Contact Dermatitis 2016;75:230-9.

31. Drucker AM, Li WQ, Lin L, et al. Atopic dermatitis (eczema) in US female nurses: lifestyle risk factors and atopic comorbidities. Br J Dermatol 2016;174:1395-7.

32. Keegel T, Nixon RL. Wet work and healthcare workers: use of hand disinfectants not associated with self-reported eczema. Br J Dermatol 2018;178:324-5.

33. Ibler KS, Jemec GB, Diepgen TL, et al. Skin care education and individual counselling versus treatment as usual in healthcare workers with hand eczema: randomised clinical trial. BMJ 2012;345:e7822.

34. Barnes S, Stuart R, Redley B. Health care worker sensitivity to chlorhexidine-based hand hygiene solutions: A cross-sectional survey. Am J Infect Control 2019;47:933-7.

35. Rönsch H, Apfelbacher C, Brans R, et al. Protocol for the development of a core domain set for hand eczema trials. J Eur Acad Dermatol Venereol 2020. [Epub ahead of print].

36. Coenraads PJ. Hand eczema. N Engl J Med 2012;367:1829-37.

37. Andrees V, John SM, Nienhaus A, et al. Economic 
evaluation of a tertiary prevention program for occupational skin diseases in Germany. Contact Dermatitis 2020;82:361-9.

38. Carøe TK, Ebbehøj NE, Bonde JP, et al. Occupational hand eczema and/or contact urticaria: factors associated with change of profession or not remaining in the workforce. Contact Dermatitis 2018;78:55-63.

39. Ibler KS, Jemec GB, Garvey LH, et al. Prevalence of delayed-type and immediate-type hypersensitivity in healthcare workers with hand eczema. Contact Dermatitis

Cite this article as: Huang D, Tang Z, Qiu X, Liu X, Guo Z, Yang B, Guo Q, Xiong H. Hand eczema among healthcare workers in Guangzhou City: a cross-sectional study. Ann Transl Med 2020;8(24):1664. doi: 10.21037/atm-20-7652
2016;75:223-9.

40. van der Meer EW, Boot CR, van der Gulden JW, et al. Hand eczema among healthcare professionals in the Netherlands: prevalence, absenteeism, and presenteeism. Contact Dermatitis 2013;69:164-71.

41. Wei J, Jaleel T, Macleod AS, et al. Inverted U-shaped relationship between vitamin D and ever-reported eczema in US adults. Allergy 2019;74:964-75.

(English Language Editor: B. Draper) 


\section{Supplementary}

Table S1 Association between risk factors and hand eczema-logistic regression analysis

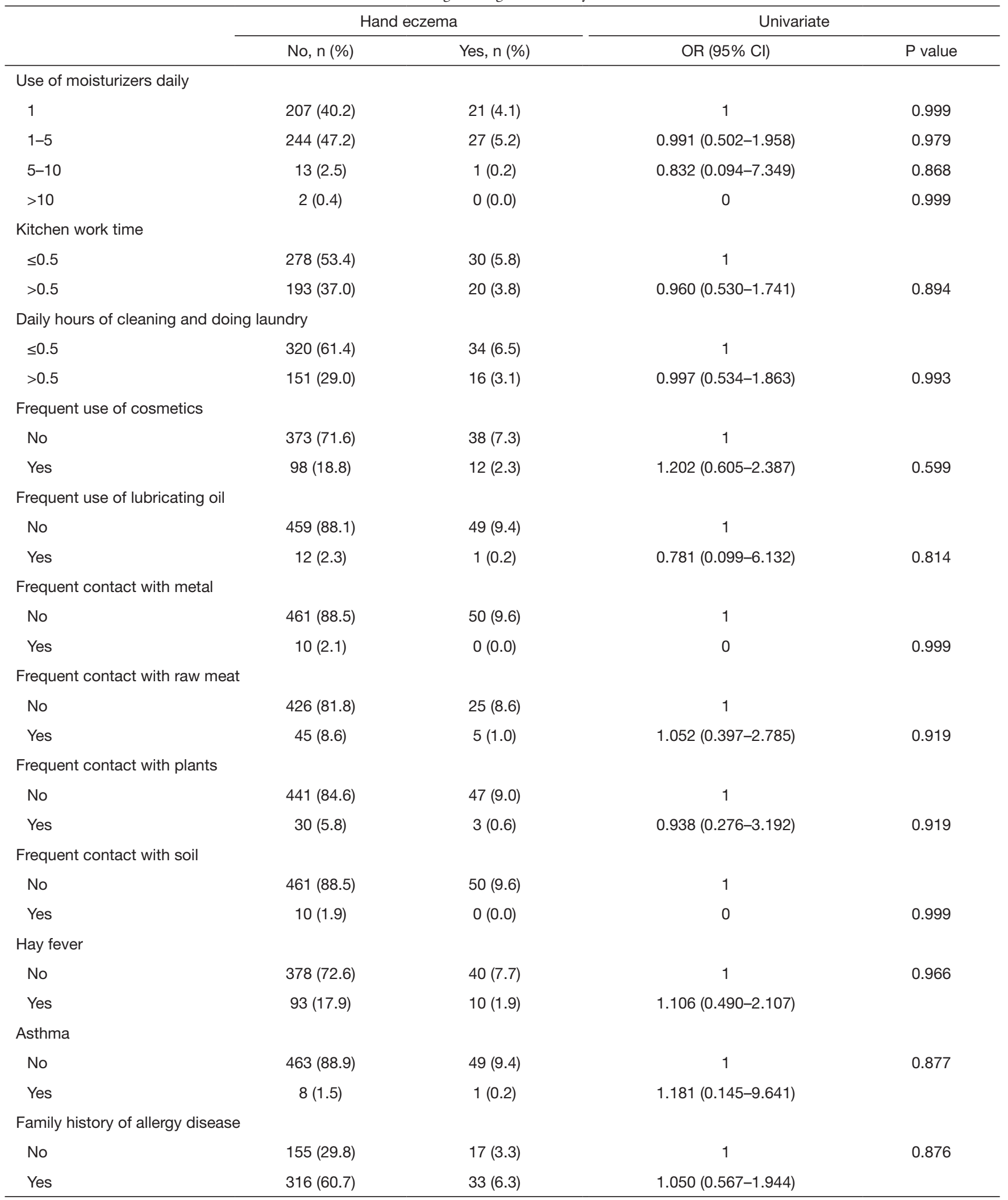

OR, odds ratio; $\mathrm{Cl}$, confidence interval. 